\title{
Bibliographic Verification for Interlibrary Loan: Is It Necessary?
}

\section{Jo Ann Bell and Susan Speer}

The model Interlibrary Loan Code states that "All items requested shall be verified . . . and sources of verification cited." During a three-month study involving approximately 900 requests, the Health Sciences Library at East Carolina University examined the necessity and effectiveness of prerequest bibliographic verification. This paper reports the results of the research and how interlibrary loan policies might be affected.

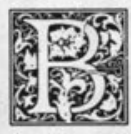

ibliographic verification is a standard interlibrary loan (ILL) practice required by the ALA Interlibrary Loan Code. A verified request is assumed to reduce the time necessary for the lending library to locate the needed item, thus reducing the client's wait. However, the verification process appears to require excessive time, because the borrowing library must attempt to verify every request before sending it to another library. This step can be especially time-consuming for those articles published so recently that they are not yet indexed. In the case of new journal titles, even the journal itself may not be indexed. Further, it appears to the verifier that almost all of the citations are already correct when submitted. Since no published research on this topic could be found, the Health Sciences Library undertook a study to determine the degree to which interlibrary loan requests were bibliographically correct and complete when submitted. Also, could a trained verifier identify incorrect or incomplete requests and thereby limit verification to those items really needing it?
The study focused on seven questions.

1. How many interlibrary loan requests are correct upon receipt?

2. Which bibliographic elements are most likely to be incorrect or incomplete?

3. Are some elements more critical than others to the ability of the lending library to supply an interlibrary loan without expending extra effort?

4. How many requests needed critical elements added/corrected during the verification process?

5. What errors occur?

a. Are there patterns associated with occurrence of errors?

b. Are some departments or clients more likely to submit requests with critical errors than others?

c. Does the age of the publication in which the request appears relate to the error rate?

d. Is the error rate significantly lower for citations for which a source is given?

e. Are requests with one error likely to have additional errors?

f. Do errors occur more frequently in

Jo Ann Bell is Director, and Susan Speer is Systems Librarian, formerly Circulation Librarian, at Health Sciences Library, East Carolina University, Greenville, North Carolina 27858. 
some bibliographic elements than in others?

6. What is the mean time needed to verify requests, and is there a statistically significant difference in the fill time between verified and unverified requests?

7. Is it possible for the interlibrary loan technician to identify accurately those requests requiring verification?

\section{METHODOLOGY}

Library clients submit photocopy and interlibrary loan requests on individual request forms. They are not required to verify requests prior to submitting to the Health Sciences Library (HSL) at East Carolina University. Many clients submit photocopies or cutouts from online searches on the ILL request forms. These requests are -not verified. An attempt is made to verify all other requests prior to sending them to another library.

A form was designed to attach to the back of each ILL request to simplify the recording of data as the request was processed. The dates on which the request was received from the client, verified, mailed to the lending library, and received were recorded, as were the sources searched in the verification process and the bibliographic elements on each request that were supplied or corrected during verification.

\section{FINDINGS}

During the period of the study, 835 interlibrary loan requests were received. Of that number, 217 came from computer

TABLE 1

\section{ANALYSIS OF REQUESTS RECEIVED}

\begin{tabular}{ll}
\hline \hline 835 & Requests received \\
217 & From computer search \\
110 & Unable to verify \\
508 & Verified \\
\hline
\end{tabular}

searches; these requests were not analyzed in the study, because we consider such requests already verified. This study dealt with the 618 remaining requests.

\section{Occurrence of Errors and Missing Elements}

Of the 618 requests, 110 were never verified, although they were searched in both manual and online sources. Therefore, for almost 18 percent of the requests, the time spent attempting verification did not improve the citations submitted. Our analysis of errors and missing data elements was confined to the remaining 508 verified requests. There were 200 requests with one or more bibliographic elements missing, and forty-two had one or more errors corrected. In addition, seventy requests had only part of the article title given. Of course, in some cases requests with missing data also contained errors. There were 242 (47.6 percent) of the requests with an error, missing data, or part of the article title missing; approximately 52 percent were correct as submitted.

To train interlibrary loan technicians to spot errors in requests, it is important to identify those request elements likely to be incorrect or incomplete. A review of table 3 reveals that the month and the issue number were most often missing and that the article title was the most frequently incomplete item. The journal title was most often incorrect, but this was true for less than 4 percent of the requests.

\section{Critical Bibliographic Elements}

The importance of the various bibliographic elements varies. Therefore, an error in the second author's name-or for that matter in the first author's name-is not as important as an error in the journal title. Further, some errors or omissions are unimportant if other key elements are accurate and complete.

For the purposes of this study, a critical bibliographic element was defined as one that if missing or incorrect would result in the lending library spending more time locating the article than would have been required had that element been present and/ or correct. It was decided that, for optimal efficiency, the lending library must have the author's last name or the title of the article, the title of the journal, the volume and the issue or month in which the article appeared and the beginning page. How- 
TABLE 2

DISTRIBUTION OF "ERRORS" IN INTERLIBRARY LOAN REQUESTS

\begin{tabular}{lcccc}
\hline \hline $\begin{array}{l}\text { Number of Errors } \\
\text { Per Request }\end{array}$ & $\begin{array}{c}\text { With Missing } \\
\text { Elements }\end{array}$ & $\begin{array}{c}\text { Percent of Requests } \\
\text { With Errors }\end{array}$ & $\begin{array}{c}\text { Missing Part } \\
\text { of Title }\end{array}$ & $\begin{array}{c}\text { Total with } \\
\text { Corrections }\end{array}$ \\
\hline 0 & 60.6 & 91.7 & 86.2 & 52.3 \\
1 & 17.3 & 6.5 & 13.6 & 18.9 \\
2 & 13.6 & 1.4 & 0.2 & 14.2 \\
3 & 7.1 & 0.2 & 0.0 & 11.0 \\
4 & 1.0 & 0.0 & 0.0 & 2.0 \\
5 & 0.2 & 0.2 & 0.0 & 1.4 \\
$7+$ & 0.2 & 0.0 & 0.0 & 0.2 \\
TOTAL & 100.0 & 100.0 & 100.0 & 100.0 \\
\hline
\end{tabular}

TABLE 3

DISTRIBUTION OF CORRECTIONS AMONG BIBLIOGRAPHIC ELEMENTS

\begin{tabular}{lccc}
\hline \hline Bibliographic Element & $\begin{array}{c}\text { Corrected } \\
(\%)\end{array}$ & $\begin{array}{c}\text { Missing Info } \\
\text { Supplied } \\
(\%)\end{array}$ & $\begin{array}{c}\text { Minor change } \\
\text { made } \\
(\%)\end{array}$ \\
\hline Journal title & 2.8 & 0.2 & 0.2 \\
Author: last name & 1.6 & 1.8 & 0.2 \\
Author: first name & 0.6 & 9.1 & 0 \\
Second author & 0.2 & 3.5 & 0 \\
Volume & 1.0 & 1.0 & 0 \\
Issue & 0.6 & 19.1 & 0 \\
Month & 0.4 & 22.4 & 0 \\
Year & 0.8 & 2.6 & 0.4 \\
Beginning page & 2.6 & 1.6 & 13.4 \\
Article title & 0.4 & 10.8 & \\
\hline
\end{tabular}

TABLE 4

ANALYSIS OF CORRECTED AND MISSING/KEY BIBLIOGRAPHIC ELEMENTS

\begin{tabular}{lccc}
\hline \hline Bibliographic Element & $\begin{array}{c}\text { Incorrect } \\
(\%)\end{array}$ & $\begin{array}{c}\text { Missing } \\
(\%)\end{array}$ & $\begin{array}{c}\text { Combination } \\
\text { of } \\
\text { orrorssing } \\
(\%)\end{array}$ \\
\hline No incorrect/missing element & 93.4 & 62.2 & 98.0 \\
Journal title & 2.8 & 0.2 & \\
Beginning page & 2.6 & 1.6 & 0.4 \\
Author last name/title & 1.0 & 0.4 & 0.6 \\
Volumel & 0.2 & 1.0 & 1.0 \\
$\quad$ Issue & & 18.9 & \\
Month & & & \\
\hline
\end{tabular}

ever, not all of these elements may be necessary for locating an article. Minimally the lending library needs only the author's last name or the title of the article, the title of the journal, the volume, and the beginning page.

It was hypothesized that although the lack of an issue number or the month might slow up location in journal volumes not continuously paged, these elements are not always necessary because most journals are continuously paged. To test this assumption, the fill time for unverified requests for which the issue/number/ date was missing was compared with the fill time for the verified requests. The mean time required for lending libraries to supply requests for which the issue and/or 
AUTHOR'S LAST NAME OR

TITLE OF ARTICLE

TITLE OF JOURNAL

VOLUME

I SSUE NUMBER OR MONTH
AUTHOR'S LAST NAME OR

TITLE OF ARTICLE

TITLE OF JOURNAL

VOLUME

BEGINNING PAGE NUMBER

BEGINNING PAGE NUMBER

\section{FIGURE 1}

Key Bibliographic Elements

month was given was slightly more than sixteen days, while the mean fill time for requests without these elements was approximately eighteen and one-half days.

After the key bibliographic elements were selected, the requests were analyzed to determine how many contained errors or omissions in these key elements.

One hundred and forty-six requests were missing at least one of the key bibliographic elements. Fifteen of these requests had an incorrect or incomplete journal title, and twenty-one had an incorrect beginning page number or were missing the page number. None of these "errors" was in the same request; therefore, thirty-six requests contained errors in these primary bibliographic elements. Other errors included incorrect or missing volume and issue numbers.

\section{"Among the requests with mini- mally complete citations, that is, cita- tions without the issue or month, only 8.9 percent of all the citations re- quired verification."}

Examining the requests in light of the definition of optimally complete citations, it was found that 28.8 percent were missing at least one key bibliographic element.
However, among the requests with minimally complete citations, that is, citations without the issue or month, only 8.9 percent of all the citations required verification.

\section{Patterns Associated with Occurrence of Errors}

Although there was interest in measuring the occurrence of errors in interlibrary loan requests, it was also important to determine if patterns are associated with the occurrence of errors. If such patterns exist, it should be possible to train an ILL assistant to spot the likely occurrence of errors, even unobvious ones. The authors examined data on the clients and departments submitting requests, the age of the journal issue in which the requested article appeared, as well as the occurrence of errors in citations for which the source is given and the probability of multiple errors in a request when one error is detected.

All requests in which one or more of the critical bibliographic elements was missing or incorrect were examined. Almost a quarter of the errors in the critical elements were made by one client: no other client had more than two requests with errors/omissions in critical elements. Further, it should be noted that the client with the highest number of critical errors is known as "usually submitting accurate, but incomplete requests." Slightly more than 10 percent of his requests contained 
errors in critical data elements. Therefore, it may not be possible to make assumptions about a given client's accuracy without closely monitoring the requests over a period of time. A similar conclusion can be drawn about departments. If one considers only the critical data elements, one department (that of the client already described above and supplemented by one additional client) accounted for 25 percent of the requests with errors in critical data elements.

The occurrence of errors, omissions, and minor changes was analyzed by the age of the article. A one-way analysis of variance indicated that differences among the groups were significant. For the error rate the difference is significant at the .04 level and for missing data at the .007 level. An exact linear relationship does not exist. As the age of the articles increases the number of citation errors or missing elements increase, but for articles published more than ten years ago, the number of errors or missing elements decreases.

Requests for which the citation sources were not given were significantly more likely to have errors and/or omissions in them. T-tests of the differences in the mean number of errors/omissions per request were significant at the .0009 level.

Referring to table 1 it can be seen that the greatest number of requests had only one missing or incorrect element. Therefore, it does not appear that requests with one error are particularly likely to have another error. However, the occurrence of multiple missing items is likely. In many cases these multiple missing items consisted of the issue, month, and year of publication. That is, many requests lacked at least two if not all three of these elements.

To assess the effectiveness of verification, the fill time needs to be examined for verified and unverified requests. Table 6 shows the mean processing times for those requests verified and those not verified. The internal and external processing times were greater for the unverified requests. A t-test was performed to test for significant difference between the processing times for verified and unverified requests. The differences in these times were significant at the .0001 level for the

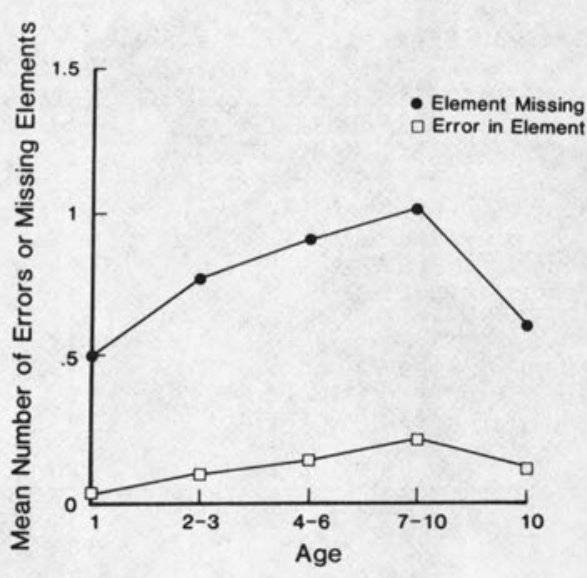

FIGURE 2

Relationship of Age to Missing and/or Incorrect Elements

time to verify the requests, the total internal processing time, and the total processing time. However, the difference between the time required for the lending library to supply unverified requests and verified requests was not significant.

\section{Verification Decision Accuracy}

As each request was received, the interlibrary loan technician indicated whether she felt that request should be verified. Table 7 shows the interlibrary loan technician's decision and the number of errors/ omissions in each of these requests. The means are higher for those interlibrary loans the technician indicated should be verified. Further, the mean time searching to verify was almost double for those the interlibrary loan technician indicated should be verified. Her verification decisions in fact paralleled very closely our definition of a minimally accurate citation-that is, she did not consider the issue/month necessary.

\section{SUMMARY OF FINDINGS}

While almost 48 percent of the citations had an error or were missing data, approximately 71 percent met the standard of an optimally complete and correct citation, and only 8.9 percent of the requests failed to meet the standard of a minimally complete and accurate citation. The is- 
TABLE 5

ANALYSIS OF ERRORS/MISSING ELEMENTS

\begin{tabular}{lrr}
\hline \hline & Number & $\%$ \\
\hline Total requests analyzed & 508 & \\
$\begin{array}{l}\text { Requests with at least one bibliographic element* } \\
\text { missing or incorrect }\end{array}$ & 242 & 47.6 \\
$\begin{array}{l}\text { Requests with a key bibliographic element } \\
\text { missing or incorrect }\end{array}$ & 146 & 28.8 \\
Requests failing to meet minimal citation standard & 45 & 8.9 \\
\hline $\begin{array}{l}\text { "Bibliographic Element }=\text { Author's last name,t author's first name, second author, title of article, }+ \text { journal title, }+ \text { volume,t is- } \\
\text { sue/month, + beginning page number, year. } \\
\text { tKey bibliographic element }\end{array}$ &
\end{tabular}

TABLE 6

MEAN PROCESSING TIMES

\begin{tabular}{lcc}
\hline \hline & Verified & Not Verified \\
\hline Time to verify request & 1.43 Days & 4.45 Days $^{*}$ \\
Total internal processing time & 3.88 & $8.63{ }^{*}$ \\
External processing time & 16.15 & 23.16 \\
Total processing time & 20.63 & 35.39 * \\
$N$ & 508 & 110 \\
\hline
\end{tabular}

-The differences in these values are significant at the .0001 level

TABLE 7

ANALYSIS OF VERIFICATION DECISION

\begin{tabular}{lccc}
\hline \hline & $\begin{array}{c}\text { Mean Number of } \\
\text { Errors }\end{array}$ & $\begin{array}{c}\text { Mean Number of } \\
\text { Missing Elements }\end{array}$ & $\begin{array}{c}\text { Mean Time } \\
\text { Searching }\end{array}$ \\
\hline Decision: Verify & .20 & .97 & 3.85 \\
Decision: Do Not Verify & .10 & .71 & 1.77 \\
\hline
\end{tabular}

sue/month was the element most often missing, and processing time for the lending library was significantly greater for these requests. It also took longer to acquire unverified requests. Data were examined for the requests that were not verified to see if reasons could be identified for their fill time being so much longer. It was discovered that one case required 264 days for filling. By removing this case and recomputing the external processing time it was found that lending libraries required approximately sixteen days to process verified requests and twenty-one days to process unverified requests. Therefore, even with the extreme case removed, the processing time of unverified requests still re- quired a significantly longer time period than did the verified requests.

The cost of verifying interlibrary loans for the library and the client is considerable. The mean time to verify requests even when they are complete and accurate was 2.9 minutes per request. Additional direct costs occur when it is necessary to use online sources to verify requests.

\section{CONCLUSION}

Whether the lending library really needs a complete bibliographic citation to supply the requested item is questionable. Would libraries realize a net savings of time if requests not obviously incomplete or inaccurate are sent without verification? 
Would it be reasonable to submit requests that appear to be accurate and complete without attempting to verify them and to submit requests that cannot be verified although an attempt has been made to do so? The lending library would take no responsibility for verifying requests and would not hesitate to return any requests that could not be located as cited by the borrowing library. The borrowing library would assume the consequences if the item could not be supplied or if the item received was not the one desired. Because electronic mail is widely used to send requests, the lending library could return immediately any unlocated requests.

The accuracy of error recognition is improved when the technician begins to search for a source for the requests. Incorrect journal titles become obvious when one cannot find a lending library for a given title. Errors in volumes and years also become apparent at this point. Thus clients might not experience any greater delay with this approach than with the current approach that requires an attempt to verify all requests.

The HSL has an understanding with the three other academic health science libraries in North Carolina to process requests in this manner. This procedure has been followed for two years and no problems have resulted from this modification. The borrowing library sends requests as soon as it can identify a holding library. It would be interesting to replicate this study with the modified procedure to de- termine the impact on fill time.

Although modification of current procedures may appear beneficial, the ethical implications of these changes should be considered. Is it ethical for the borrowing library to pass on its work to the lending library? In some instances, even if the borrowing library has stated that it does not expect the lending library to search for requested items, personnel in that library may hesitate to "give up" on a request. Also, the lending library incurs direct expense for returning incorrect requests to the borrowing library.

There is also a positive side to procedure modification. All libraries could save the time now spent on searching requests that appear to be accurate and complete and could limit the time spent attempting to verify any request. In many cases, clients would receive needed information sooner. Also, clients will find through experience that submission of accurate and complete requests results in receipt of needed information more quickly. And, they are more likely to perceive the additional time required when inaccurate and incomplete requests are submitted.

At this time, individual libraries should reach agreement with each other to modify the verification procedure on mutually acceptable terms. In this way the value of modifying these procedures can be evaluated widely but with open knowledge and acceptance of that modification by all participating parties. 